\title{
DYSMENORRHEA AMONG FEMALE MEDICAL SCIENCES STUDENTS IN MACHS: PREVALENCE, PREDICTORS, AND OUTCOME
}

\author{
LATHA S KANNAN ${ }^{1 *}$, HASSAN EG ${ }^{1,2}$, SHARELL LEWIS ${ }^{1}$, NISHA SIVAPALAN ${ }^{1}$, BERNADETTE CASINGAL $^{1}$ \\ PALANIVEL RM ${ }^{3}$
}

${ }^{1}$ Department of Nursing, Mohammed Al-Mana College for Medical Sciences, P.O. Box 3915, Dammam 34222, Saudi Arabia. ${ }^{2}$ Department

of Medical Surgical Nursing, Faculty of Nursing, Cairo University, Egypt. ${ }^{3}$ Quality and Measurement Department, Deanship of Quality and Academic Accreditation, Imam Abdulrahman Bin Faisal University, P.0. Box 1982, Dammam 31441, Saudi Arabia. Email: lathak@machs.edu.sa

Received: 01 April 2020, Revised and Accepted: 12 May 2020

\section{ABSTRACT}

Objective: This study intended to determine the prevalence, predictors, and outcome of dysmenorrhea among female medical sciences students at Mohammed Al-Mana College for Medical Sciences (MACHS), Dammam, Saudi Arabia.

Methods: A cross-sectional study was adopted, and 292 female medical sciences students of MACHS were selected using stratified random sampling. A semi-structured and self- administrated questionnaire was used to collect personal and socio-demographic information from the selected female medical sciences students. The information about menstrual history, stress, and smoking were also gathered. The data analysis was carried out using the descriptive statistics and Chi-square test.

Results: The prevalence of dysmenorrhea was 73.28\% among female medical sciences students. Concerning the signs and symptoms of dysmenorrhea, the abdominal pain was predominant symptoms among $73.28 \%$ of the respondents, and it was found to be statistically significant (p $\leq 0.05$ ). Sleep disturbance was observed as the prominent outcome of dysmenorrhea, as reported by $64 \%$ of the respondents.

Conclusions: A high prevalence of dysmenorrhea was found among female medical sciences students at MACHS. Hence, health promotion, screening programs, and stress management courses are recommended for the female medical sciences students to overcome the adverse outcomes of dysmenorrhea.

Keywords: Dysmenorrhea, Medical sciences, Students, Prevalence, Outcome.

(C) 2020 The Authors. Published by Innovare Academic Sciences Pvt Ltd. This is an open access article under the CC BY license (http://creativecommons. org/licenses/by/4. 0/) DOI: http://dx.doi.org/10.22159/ajpcr.2020.v13i6.38190

\section{INTRODUCTION}

Menstrual disorder is a significant health problem among females during their reproductive age. Dysmenorrhea or painful menstruation is very common among females. It could even prevent them from performing normal daily activities. It is often accompanied by symptoms such as breast pain, abdominal pain, irritability, and fatigue. Primary dysmenorrhea denotes painful menstruation without underlying pathology, whereas secondary dysmenorrhea is associated with underlying pathology such as endometriosis. Primary dysmenorrhea is very common among young-aged females [1].

During menstruation, excess secretion of prostaglandin occurs from the endometrial. This condition might lead to primary dysmenorrhea. As a result, females may experience a colicky pain over the lower abdomen and sometimes in the sacral region in the early hours of menstruation. A study conducted among adolescent students in Assiut City, Egypt, indicated that there is a significant association between earlier menarche, longer cycle length, bleed length, heavy bleeding, and irregular cycle and dysmenorrhea [2]. Another study conducted in Jordan emphasized the association of family history with dysmenorrhea [3]. The discomforts associated with dysmenorrhea showed a significant impact on the social life of people. It is considered as a significant reason for absenteeism in universities and work. Although the prevalence of dysmenorrhea is high among adolescents and young adults, most of them do not seek any medical aid, or at times, they are even undertreated [4].

Besides, only a few studies have been conducted related to the gynecological problems of young females, specifically in Arab countries. Hence, this study aimed to determine the prevalence of dysmenorrhea, predictors of its pain, and outcomes of dysmenorrhea among students in
Mohammed Al-Mana College for Medical Sciences (MACHS), Dammam, Saudi Arabia.

\section{METHODS}

\section{Research design}

A cross-sectional study was adopted in this study. The population of this study covered female students ranging from the $1^{\text {st }}$ year $-4^{\text {th }}$ (final) year belonging to the health sciences programs such as nursing, pharmacy, and CLS at MACHS. A total of 292 female medical science students were selected using stratified random sampling. All male students and female students who refused to participate in this study were excluded from the study. The ethical approval for this study was obtained from the Institutional Review Board of the Scientific Research Unit, (Reference Number: SR/RP/15) and conformed to the ethical standards of the Helsinki Declaration.

A semi-structured and self-administrated questionnaire was used for data collection from the selected students. The questionnaire was developed in both Arabic and English languages with the consideration of the basic year students. The researcher has developed the questionnaire used by reviewing the previous literature, discussing with several experts in the field of gynecology and obstetrics doctors and nursing. This questionnaire comprised four major sections in addition to the socio-demographic characteristics of students. The questions are framed concerning menstruation, symptoms accompanying dysmenorrhea, and outcomes of dysmenorrhea.

The data were analyzed using SPSS 25. Descriptive statistics used to calculate the mean and percentage for the variables. A Pearson Chisquare test was used to determine the association between signs and symptoms and outcome sat a $5 \%$ level of significance $(\mathrm{p}<0.05)$. 


\section{RESULTS}

Table 1 described the basic socio-demographic characteristics of the respondents. The total number of female medical sciences students responded to the questionnaire was 292 . The majority (73.97\%) of them were single, and $90.41 \%$ of the respondents were living with their families. Most (89.72\%) of the respondents were non-smokers. More than half (56.84\%) of the respondents reported as they do regular exercises in leisure time. The data on the anthropometric measurements revealed that $90.06 \%$ of the respondents had a normal body mass index.

Further, the menstruation-related information about the respondents is described in Table 2. On reviewing the results, the percentage of respondents that reported their duration between menstrual cycles of more than 30 days is $58.21 \%$. The percentage of respondents about the duration of menstrual cycles and the amount of bleeding was observed as $59.24 \%$ and $72 \%$, respectively. The majority $(74.31 \%)$ of the respondents attained menarche below or at the age of 15 .

Table 3 represented the data on the symptoms experienced by the respondents during menstruation. The symptoms can be listed as breast pain, abdomen pain, irritability, fatigue, dizziness, leg cramps, anxiety, nausea, vomiting, and emotional disturbances (anger, depressed mood, etc.). The respondents reported the symptoms that accompany dysmenorrhea was predominantly abdominal pain (73.28\%), followed by emotional disturbances such as anger and depressed mood (67.12\%). The symptoms such as breast pain, abdomen pain, irritability, leg cramps, anxiety, nausea, vomiting, and emotional disturbances showed a statistically significant association with dysmenorrhea $(\mathrm{p}<0.05)$.

Table 1: Socio-demographic characteristics of participants $(n=292)$

\begin{tabular}{|c|c|}
\hline Socio-demographic characteristics & n (\%) \\
\hline \multicolumn{2}{|l|}{ Age in years } \\
\hline $15-20$ & $71(24.31)$ \\
\hline 20 and more & $221(75.68)$ \\
\hline \multicolumn{2}{|l|}{ Academic year } \\
\hline Foundation year & $81(27.39)$ \\
\hline Health science students & $211(72.26)$ \\
\hline \multicolumn{2}{|l|}{ Marital status } \\
\hline Single & 216 (73.97) \\
\hline Married & $76(26.02)$ \\
\hline \multicolumn{2}{|l|}{ Residency } \\
\hline With family & $264(90.41)$ \\
\hline Staying alone & $22(7.5)$ \\
\hline Staying with friends/relatives & $6(2.05)$ \\
\hline \multicolumn{2}{|l|}{ Smoking } \\
\hline Yes & 30 (10.27) \\
\hline No & $262(89.72)$ \\
\hline \multicolumn{2}{|l|}{ Practice physical exercise } \\
\hline Yes & $166(56.84)$ \\
\hline No & $126(43.15)$ \\
\hline \multicolumn{2}{|l|}{ Stress } \\
\hline Yes & 169 (57.87) \\
\hline No & $123(42.12)$ \\
\hline \multicolumn{2}{|l|}{ Weight in kilograms } \\
\hline $30-35$ & $7(2.3)$ \\
\hline $35.1-40$ & $17(5.82)$ \\
\hline $40.1-45$ & $40(13.69)$ \\
\hline $45.1-50$ & $228(78.08)$ \\
\hline \multicolumn{2}{|l|}{ Height } \\
\hline $120-130 \mathrm{~cm}$ & $2(0.6)$ \\
\hline $131-140 \mathrm{~cm}$ & $18(6.16)$ \\
\hline $141-150 \mathrm{~cm}$ & 47 (16.09) \\
\hline $151-160 \mathrm{~cm}$ & $225(77.05)$ \\
\hline \multicolumn{2}{|l|}{ BMI } \\
\hline Normal & $263(90.06)$ \\
\hline Overweight & $1(0.34)$ \\
\hline Obesity & $28(9.5)$ \\
\hline
\end{tabular}

BMI: Body mass index
Moreover, the different outcomes of dysmenorrhea among the complainers are shown in Table 4. Sleep disturbance is identified as the most prevalent outcome $(64.0 \%)$ of dysmenorrhea, followed by limited daily activity (55.13\%), decreased social activities (53.42\%), emotional instability (52.73\%), reduced concentration (48.92\%), and absenteeism from university (37.67\%). Sleep disturbance and absenteeism from college/university were observed as the statistically significant outcomes of dysmenorrhea $(\mathrm{p}<0.05)$.

\section{DISCUSSION}

This study was conducted to determine the prevalence of dysmenorrhea, the predictors of pain, and the outcome of dysmenorrhea among female medical sciences' students of MACHS. In this study, the prevalence of dysmenorrhea was observed as $73.28 \%$ among female that found medical sciences students. This finding is consistent with a recent study done among university health science students of Northern Ethiopia found the prevalence of dysmenorrhea as 71.8\% [5]. Similarly, a study done in Saudi Arabia reported the prevalence of dysmenorrhea as70.6\%among university students [6]. On the other hand, the

Table 2: Menstruation-related information among female medical sciences students in Dammam Saudi Arabia $(n=292)$

\begin{tabular}{ll}
\hline Variables & $\mathbf{n}(\mathbf{\%})$ \\
\hline Age of menarche in years & \\
$\quad$ Below or at 15 & $217(74.31)$ \\
$\quad$ Above 15 & $75(25.68)$ \\
Duration between menstrual cycles & $122(41.78)$ \\
$\quad<30$ days & $170(58.21)$ \\
$\quad$ More than 30 days & \\
Duration of menstruation & $173(59.24)$ \\
$\quad<5$ days & $119(40.75)$ \\
$\quad$ More than 5 days & \\
Amount of bleeding & $82(28)$ \\
$\quad<3$ pads/day & $210(72)$ \\
$\quad$ More than 3 pads/day & \\
Family history of dysmenorrhea & $58(19.86)$ \\
Yes & $234(80.13)$ \\
$\quad$ No & \\
\hline
\end{tabular}

Table 3: Symptoms accompanying dysmenorrhea among female medical sciences students in Dammam Saudi Arabia

\begin{tabular}{llll}
\hline Symptoms & Yes, $\mathbf{n}(\%)$ & No, n (\%) & P**-value \\
\hline Breast pain & $168(57.14)$ & $124(42.17)$ & $* 0.01$ \\
Abdomen pain & $214(73.28)$ & $78(26.71)$ & 0.00 \\
Irritability & $105(35.95)$ & $187(64.05)$ & 0.00 \\
Fatigue & $139(47.60)$ & $153(52.39)$ & 0.41 \\
Dizziness & $149(51.02)$ & $143(48.97)$ & 0.73 \\
Leg cramps & $98(40.49)$ & $194(66.43)$ & $* 0.00$ \\
Anxiety & $165(56.50)$ & $127(43.49)$ & 0.03 \\
Nausea vomiting & $115(39.38)$ & $177(60.61)$ & $* 0.00$ \\
Emotional disturbances & $196(67.12)$ & $96(32.87)$ & $* 0.00$ \\
(anger, depressed mood, etc.) & & & \\
\hline
\end{tabular}

${ }^{*}$ p-value calculated with Chi-square test, $\mathrm{p} \leq 0.05$ consider as significant

Table 4: Outcomes of dysmenorrhea among female medical sciences students in Dammam Saudi Arabia

\begin{tabular}{llll}
\hline Symptoms & Yes (\%) & No (\%) & ${ }^{*}$ p-value \\
\hline Emotional instability & $154(52.73)$ & $138(47.27)$ & 0.35 \\
Limited daily activity & $161(55.13)$ & $131(44.87)$ & 0.08 \\
Sleep disturbance & $187(64)$ & $105(36)$ & ${ }^{*} 0.00$ \\
Reduced concentration & $143(48.92)$ & $149(51.08)$ & 0.73 \\
Decreased social activities & $156(53.42)$ & $136(46.6)$ & 0.09 \\
Absenteeism from college/ & $110(37.67)$ & $182(62.32)$ & $* 0.00$ \\
university & & & \\
\hline
\end{tabular}

*p-value calculated with Chi-square test, $\mathrm{p} \leq 0.05$ consider as significant 
prevalence of dysmenorrhea was observed as $61.33 \%$ among Indian adolescent girls [7]. Moreover, the prevalence of primary dysmenorrhea is highly underestimated, yet challenging to determine, because few affected women seek medical treatment, despite the substantial distress experienced, as many consider the pain to be a regular part of the menstrual cycle rather than a disorder [8].

An analysis of demographic variables indicated that the majority of the female medical sciences' students were single $(73.97 \%)$ and living with their families (90.4\%). These findings are in accord with the results of Ibrahim et al. [9]. Following the assessment of signs and symptoms of dysmenorrhea, abdominal pain was observed as the predominant outcome among $73.28 \%$ of the female medical sciences students. It was found to be highly statistically significant $(p \leq 0.05)$. This finding is in line with the results of Yesuf et al. [5], who indicated that $67.4 \%$ of the university students experienced abdominal pain from dysmenorrhea.

Besides, sleep disturbance was observed as a prominent outcome of dysmenorrheal reported by $64 \%$ of the female medical sciences' students. This finding is supported by a study in Saudi Arabia, which reported that $54 \%$ of female medical students had sleep disturbance due to dysmenorrhea [9]. Further, the same study indicated that emotional instability was experienced by $67.5 \%$ of the participants, whereas the current study observed $52.73 \%$ of the female medical sciences' students experienced emotional instability. This study mainly pointed out toward $67.12 \%$ of the female medical sciences' students that were suffering from emotional disturbances during dysmenorrhea such as anger and depressed mood. Such emotional disturbances could have a significant impact on the outcome of dysmenorrhea, resulting in reduced concentration and affecting the social activities of the students.

Furthermore, only one-third (37.67\%) of the female medical sciences' students reported absenteeism from college/university due to dysmenorrhea. This finding is in line with a study conducted in Palestine, which reported that $31.1 \%$ of students missed school due to menstrual pain.

\section{CONCLUSIONS}

The prevalence of dysmenorrhea is high among the female medical sciences students in Saudi Arabia. The outcomes of dysmenorrhea were more emotional than physical. This outcome can negatively impact the quality of learning among female medical sciences students. Moreover, necessary measures need to be taken to counteract these effects. The most crucial thing is acknowledging the existence of the problem and seeking necessary help. This study also insists the institutions make the necessary support facilities that are required for the female students. Besides, there is a need for conducting various educational programs to enrich the knowledge of the female students about how to deal with the emotional problems by learning adaptive coping strategies, thereby improve their quality of life.

\section{Limitations}

In this study, the sample size of the study is small, making it difficult to generalize the research findings. It focused on the female medical sciences' students of only one college in Saudi Arabia. Hence, further research is warranted to cover all female students irrespective of programs offered by various colleges/universities across Saudi Arabia with larger sample size. This attempt would help to generalize the research findings. Another critical factor is the student's reluctance to acknowledge that they have dysmenorrhea. As in many cultures, dysmenorrhea is considered as one of the women's problems, which is not being more discussed. Another drawback is observed as the dysmenorrhea pain has not been categorized, making it difficult to find a correlation between dysmenorrhea and other related factors.

\section{ACKNOWLEDGMENTS}

We would like to thank all medical science students who participated in the research and Dr. Mohammad Daud Ali for his assistance in statistics and encouragement throughout the research process.

\section{AUTHORS' CONTRIBUTIONS}

The study was designed and conceptualized by Mrs. Latha and Dr. Eman. Data collection, data analysis, literature search, and manuscript preparation done by Mrs. Latha, Mrs. Sharell and Mrs. Nisha.

Editing and reviewing were done by Dr. Eman and Mrs. Latha. Dr. Palanivel contributed to data analysis and manuscript preparation. Mrs. Bernadatte assisted in the literature search.

\section{CONFLICTS OF INTEREST}

None.

\section{AUTHORS' FUNDING}

None.

\section{REFERENCES}

1. Harada T. Dysmenorrhea and endometriosis in young women. Yonago Acta Med 2013;56:81-4.

2. Mohamed EM. Epidemiology of dysmenorrhea among adolescent students in Assiut city, Egypt. Life Sci J 2012;9:348-53.

3. Mukattash TL, Tahaineh L, AlRawi N, Jarab A, Hammad H, Nuseir K. Behaviors and attitudes towards dysmenorrhea: A cross-sectional survey of 2,000 Jordanian University students. J Med J 2013;171:1-18.

4. Gagua T, Tkeshelashvili B, Gagua D. Primary dysmenorreahleading problem of adolescent gynecology. Georgian Med News 2012;207:7-14

5. Yesuf TA, Eshete NA, Sisay EA. Dysmenorrhea among University health science students, Northern Ethiopia: Impact and associated factors. Int J Reprod Med 2018;2018:9730328.

6. Alsaleem MA. Dysmenorrhea, associated symptoms, and management among students at King Khalid University, Saudi Arabia: An exploratory study. J Family Med Prim Care 2018;7:769-74.

7. Ahuja A, Sharma MK, Singh A. Impact of dysmenorrhea on quality of life of adolescent girls of Chandigarh. J Child Adolesc Behav 2016;4:3.

8. Wong LP. Attitudes towards dysmenorrhoea, impact and treatment seeking among adolescent girls: A rural school-based survey. Aust J Rural Health 2010;19:218-23.

9. Ibrahim NK, AlGhamdi MS, Al-Shaibani AN, AlAmri FA, Alharbi HA, Al-Jadani AK, et al. Dysmenorrhea among female medical students in King Abdulaziz University: Prevalence, predictors and outcome. Pak J 2015;31:1312-7. 